\title{
CONTENUS EN PROTÉINES ET EN ACIDES NUCLÉIQUES DU FOIE HYPERTROPHIE APRĖS LA LIBRE INGESTION DE DI-TERTIO-BUTYL-HYDROXY-TOLUENE (BHT) CHEZ LE RAT, LE PORC ET LE POULET EN CROISSANCE INFLUENCE DU TAUX PROTÉIQUE DE LA RATION
}

\author{
G. DURAND, G. PASCAL, B. DESMOULIN* et P. DELPECH** \\ avec la collaboration technique de Noëlle Bourgéaux \\ Station de Recherches de Nutrition, \\ Centre national de Recherches zootechniques, I. N.R.A., \\ 78350 Jouy en Josas \\ * Station de Recherches sur l'Élevage des Porcs, \\ Centre national de Recherches zootechniques, I. N.R. A., \\ 78350 Jouy en Josas \\ ** Institut national agronomique Paris-Grignon, \\ 78850 Thiverval Grignon
}

\section{RÉSUMÉ}

Les effets de l'ingestion de BHT sur l'appétit, la vitesse de croissance et l'hypertrophie hépatique sont étudiés chez le Rat, le Porc et le Poulet en croissance. L'hypertrophie hépatique est envisagée sous l'angle de l'accumulation des protéines $(N \times 6,25)$ et des acides nucléiques, l'ADN en particulier. De plus, chez le Rat, les effets de l'antioxygène sur ces mêmes facteurs sont étudiés en fonction du taux protéique du régime.

Des lots de Rats mâles reçoivent des régimes contenant o, 2 p. Ioo de BHT, et 8 p. Ioo, I3 p. Ioo ou i 8 p. Ioo de protéines. Des lots de Porcs, mâles castrés ou femelles, reçoivent des régimes contenant 0,6 p. I 00 ou I, 2 p. Ioo de BHT et I 9 p. Ioo de protéines. Des lots de Poulets mâles reçoivent des régimes contenant de 0,2 p. Ioo à $\mathrm{I}, 6 \mathrm{p}$. I0o de BHT et $24 \mathrm{p}$. Ioo de protéines. Ces lots sont comparés à des lots témoins alimentés ad libitum et, éventuellement, à des lots témoins restreints.

Les résultats permettent de dégager les points suivants :

- L'addition de BHT, à la concentration de $0,2 \mathrm{p}$. 1oo dans le régime, réduit légèrement l'appétit des Rats (de $-3 \mathrm{p}$. Ioo à $-8,5 \mathrm{p}$. IOO) ; cependant, l'addition de l'antioxygène reste sans effet sur l'appétit des Porcs, même à la concentration de I,2 p. 10o, et sur l'appétit des Poulets, même à la concentration de I,6 p. Ioo.

- La vitesse de croissance des Rats dont le régime contient 0,2 p. Ioo de BHT est équivalent à celle des témoins restreints correspondants, lorsque le régime contient suffisamment de protéines ( 3 p. IOo et I 8 p. IOO); mais elle lui est inférieure lorsque l'apport protéique est insuffisant ( 8 p. I0o). La vitesse de croissance des Porcs n'est pas modifiée, même lorsque la concentration de l'antioxygène dans le régime atteint $\mathrm{I}, 2 \mathrm{p}$. roo. La vitesse de croissance du Poulet n'est pas modifiée pour une concentration de $0,8 \mathrm{p}$. Ioo, mais diminue de $55 \mathrm{p}$. Ioo pour une concentration de $\mathrm{I}, 6$ p. roo. 
- L'addition de $\mathrm{BHT}$ dans le régime alimentaire provoque une hypertrophie hépatique chez les trois espèces, mais pour des concentrations différentes, le Rat étant le plus sensible, puis le Porc et enfin le Poulet. L'hypertrophie hépatique est généralement accompagnée d'augmentations proportionnelles des contenus en protéines et en ARN du foie ; par contre, l'effet du BHT sur l'accumulation d'ADN hépatique varie selon les espèces; cet effet est nul chez le Poulet, stimulant chez le Porc et le Rat ; cependant, chez le Rat, l'effet stimulant est contrebalancé par l'autorestriction alimentaire.

\section{INTRODUCTION}

Le di-tertio-butyl-hydroxy-toluène (BHT) est l'un des antioxygènes couramment utilisés pour la conservation des produits alimentaires sensibles à la péroxydation. Les effets biochimiques et physiologiques que l'ingestion de ce composé induit dans l'organisme ont fait l'objet d'un assez grand nombre de travaux, passés en revue récemment par Pascal et TERroine (I966 a) et Pascal (I974). Ces travaux concernent plus particulièrement les effets du BH'T :

- sur l'appétit et la vitesse de croissance (Deichmann et coll., I955; Brown et coll., I959 ; GAUNT et coll., I955 $a$ et $b$; FRAWLEY et coll., I965; PASCAL et coll., I970 ; Durand et Pascal, I973);

- sur la digestibilité des protéines et des lipides (Pascal et Durand, I970 ; PASCAL et TERROINE, I972) ;

- sur le métabolisme énergétique (Johnson et Holdsworth, I968; PASCAL et Terroine, I969 $b$, I972 ; Pascal, et Durand, I970 ; Pascal, I97I) ;

- sur le foie, dont la taille est augmentée par l'ingestion de fortes doses de l'additif ; cette hypertrophie hépatique a particulièrement retenu l'attention, et un grand nombre d'études que PASCAL (I974) analyse dans sa revue sont consacrées à ses aspects histologiques et biochimiques. Il apparaît, à ce propos, que la relation entre l'hypertrophie du foie d'une part, l'accumulation des protéines et des acides nucléiques d'autre part, est insuffisamment connue.

On relève également des études qui portent sur les relations entre le BH'T et d'autres composés, tels que la vitamine $\mathrm{E}$, ou certains agents hépatoxiques; ajoutons encore les recherches concernant les effets de l'ingestion régulière de BH'T sur la longévité ; cette question est analysée dans une récente revue (DURAND, I972).

Cependant, hormis le domaine des vitamines $\mathrm{E}$ et $\mathrm{A}$, il est à noter que très peu de travaux se rapportent à l'étude des relations entre les effets du BHT et la composition du régime alimentaire ; on peut citer, à ce propos, BRown et coll. (I959), JoHNson et HoldDSWORTh (I968), PASCAL et TERRoINE (I972) qui s'intéressent à diverses actions du BHT en fonction du taux et/ou de la nature des lipides du régime, et DURAND et PASCAL (I973) qui démontrent que le Rat mâle adulte ne peut tolérer plus de $300 \mathrm{mg} / \mathrm{kg} / \mathrm{jour}$ de 1'additif lorsque le régime ne contient que I3 p. roo de protéines équilibrées, tandis qu'il en tolère jusqu'à $630 \mathrm{mg} / \mathrm{kg} / \mathrm{j}$ lorsque le régime en contient 26 p. Ioo. Ce sont-là, à notre connaissance, avec celle de Sporn et ScHoBESCH (I96I), les seules publications relatives à cette question.

Par ailleurs, comme le font remarquer MiLner ( 1967$)$ et PASCAL et TERroine (I969a), " la quasi totalité des observations sont effectuées chez le Rat, parfois chez 
la Souris ". Toute la législation concernant 1'usage du BHT en alimentation repose sur des expériences effectuées chez ces deux rongeurs, et surtout chez le Rat.

Dans le présent travail, nous nous proposons d'étudier l'effet de l'ingestion de $\mathrm{BHT}$, ajouté à de fortes concentrations dans le régime, sur l'appétit, la vitesse de croissance et l'hypertrophie hépatique chez plusieurs espèces animales : le Rat, le Porc et le Poulet. De plus, chez le Rat, l'influence du taux protéique de la ration sur les effets du BH'T est étudiée. L'hypertrophie hépatique est surtout envisagée sous l'angle peu exploré de l'accumulation des protéines $(\mathrm{N} \times 6,25)$ et des acides nucléiques, l'ADN en particulier.

\section{MATÉRIEL, ET MÉTHODES}

$$
\text { r. - Matériel animal }
$$

I. 1. Rats.

Quatre-vingt-đix Rats mâles Wistar, âgés de 4 semaines et pesant $70 \mathrm{~g} \pm 2 \mathrm{~g}$, sont répartis en 3 groupes de 30 animaux qui reçoivent respectivement des régimes renfermant 8 p. roo, I 3 p. Ioo et 18 p. Ioo de protéines : ces régimes sont dits régimes témoins $\left(\mathrm{Rt}_{1}, \mathrm{Rt}_{2} \mathrm{et}_{\mathrm{R}} \mathrm{t}_{3}\right)$, et leur composition centésimale figure sur le tableau $\mathrm{I}$.

\section{TABLEAU I}

Rats

Composition centésimale des régimes alimentaires

\begin{tabular}{|c|c|c|c|}
\hline Régime & $\mathrm{Rt}_{1}$ & $\mathrm{Rt}_{2}$ & $\mathrm{Rt}_{3}$ \\
\hline $\begin{array}{l}\text { Protéines p. } 100 \text { du régime }\left({ }^{\mathbf{1}}\right) \\
\quad(\mathrm{N} \times \mathbf{6 , 2 5}) \ldots \ldots \ldots \ldots \ldots\end{array}$ & 8 & 13 & 18 \\
\hline $\begin{array}{l}\text { Farine de Hareng de Norvège } \\
\text { Amidon de Maïs }\left(^{(2)} \ldots \ldots \ldots \ldots\right.\end{array}$ & $\begin{array}{l}110 \\
516,7\end{array}$ & $\begin{array}{l}180 \\
446,2\end{array}$ & $\begin{array}{l}250 \\
375,7\end{array}$ \\
\hline $\begin{array}{l}\text { DL-méthionine } \ldots \ldots \ldots \ldots \\
\text { Sucre cristallisé } \ldots \ldots \ldots \ldots \ldots \\
\text { Huile d'arachide } \ldots \ldots \ldots \ldots \ldots \\
\text { Mélange minéral } \ldots \ldots \ldots \ldots \\
\text { Mélange vitaminique } \ldots \ldots \ldots \\
\text { Agar-Agar } \ldots \ldots \ldots \ldots \ldots \ldots\end{array}$ & $\begin{array}{c}0,8 \\
220 \\
92,5 \\
30 \\
10 \\
20\end{array}$ & $\begin{array}{l}1,3 \\
220 \\
92,5 \\
30 \\
10 \\
20\end{array}$ & $\begin{array}{l}1,8 \\
220 \\
92,5 \\
30 \\
10 \\
20\end{array}$ \\
\hline
\end{tabular}

(1) Par rapport à la matière sèche.

( ${ }^{2}$ Dans les régimes expérimentaux $\left(\mathrm{E}_{1}, \mathrm{E}_{2}, \mathrm{E}_{3}\right), 2 \mathrm{~g}$ de BHT sont ajoutés aux dépens de l'amidon de Maïs.

Chaque groupe est lui-même divisé en 3 lots de Io animaux :

- I lot, dit témoin $\left(\mathrm{T}_{1}, \mathrm{~T}_{2}\right.$ ou $\left.\mathrm{T}_{3}\right)$, reçoit le régime témoin correspondant à son groupe;

- I Iot, dit expérimental $\left(\mathrm{E}_{1}, \mathrm{E}_{2}\right.$ ou $\left.\mathrm{E}_{3}\right)$ reçoit le régime témoin additionné de 0,2 p. Ioo de $\mathrm{BHT}$;

- I lot, dit témoin restreint $\left(\mathrm{TR}_{1}, \mathrm{TR}_{2}\right.$ ou $\left.T \mathrm{TR}_{3}\right)$, reçoit le régime témoin, mais la quantité d'ali- 
ment distribuée à chaque animal de ce lot est alignée sur la consommation moyenne des animaux du lot E correspondant de même poids.

La pesée des Rats et la mesure de leur consommation alimentaire sont effectuées quotidiennement. Tous les lots sont sacrifiés à $300 \mathrm{~g}$ et peuvent ainsi être comparés à poids égal ; les animaux sont mis au jeûne I 5 heures avant le sacrifice, ce qui explique les pertes de poids accusées lors de la dernière pesée, qui apparaissent sur les courbes de croissance (fig. 2) ; les animaux sont saignés sous anesthésie à l'éther ; leur foie est prélevé, pesé et conservé dans l'azote liquide jusqu'au moment du traitement analytique.

\section{2. Porcs.}

Soixante-douze Porcs Large White dont 36 mâles castrés et 36 femelles, âgés de Io semaines et pesant $25 \mathrm{~kg}$ environ, sont répartis en 3 lots pour chaque sexe, soit au total 6 lots de I 2 sujets.

Un lot de castrats et un lot de femelles reçoivent un régime, dit régime témoin, contenant I9 p. Ioo de protéines et dont la composition centésimale figure sur le tableau 2 ; ces deux lots constituent les lots témoins (lots TM et TF). Les quatre autres lots dits expérimentaux, reçoivent le régime témoin additionné de $\mathrm{BHT}$, soit à la concentration de 0,6 p. Ioo (lots $\mathrm{EM}_{1} \mathrm{et} \mathrm{EF}_{1}$ ), soit à la concentration de $I_{2}, \mathrm{p}$. Ioo (lots $\mathrm{EM}_{2}$ et $\mathrm{EF}_{2}$ ). Les animaux sont pesés chaque semaine et la consommation alimentaire moyenne de chaque lot est mesurée. Tous les animaux sont abattus au poids de $100 \mathrm{~kg}$, par électrocution, après un jeûne de 15 heures; ils sont saignés aussitôt après et leur foie est prélevé ; l'organe est ensuite pesé et immédiatement broyé au hachoir à viande; une partie du broyat, roo g environ, est conservée dans l'azote liquide avant traitement.

TABI,EAU 2

Porcs

Composition centésimale du végime alimentaire

\begin{tabular}{|c|c|}
\hline Protéines $(\mathrm{N} \times 6,25)$ p. 100 du régime $\left({ }^{1}\right)$ & 19 \\
\hline Maïs $\left({ }^{2}\right) \ldots \ldots \ldots \ldots \ldots$ & 74 \\
\hline Tourteau de Soja .................. & 15 \\
\hline Farine de poisson $\ldots \ldots \ldots \ldots \ldots \ldots \ldots$ & 3 \\
\hline 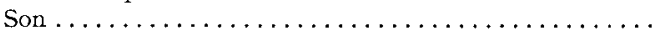 & 4 \\
\hline Mélange minéral $\ldots \ldots \ldots \ldots \ldots \ldots \ldots$ & 3 \\
\hline Mélange vitaminique $\ldots \ldots \ldots \ldots \ldots \ldots \ldots \ldots$ & 1 \\
\hline
\end{tabular}

(1) Par rapport à la matière sèche.

(2) Dans les régimes expérimentaux : 0,6 p. 100 ou 1,2 p. 100 de BHT sont ajoutés aux dépens du Maîs.

\section{3. Poulets.}

Trente-six Poulets mâles Hubard âgés de 5 semaines, pesant $94^{8} \pm 50 \mathrm{~g}$, sont répartis en 3 lots de I 2 sujets qui sont alimentés comme indiqué ci-dessous :

a) De l'âge de 5 semaines à celui de 9 semaines:

- I lot, dit lot témoin $(T)$, reçoit un régime contenant 24 p. roo de protéines et 8 p. roo de lipides ; ce régime constitue le régime témoin $(\mathrm{Rt})$;

- I lot $(\mathrm{A})$ reçoit le régime témoin additionné de 0,2 p. Ioo de BHT (régime $\left(\operatorname{Ra}_{1}\right)$;

- I lot (B) reçoit le régime témoin additionné de 0,4 p. roo de BHT (régime $\mathrm{Rb}_{1}$ ).

b) De l'âge de 9 semaines à celui de 11 semaines:

- le lot $\mathrm{T}$ reçoit encore le régime témoin (régime $\mathrm{Rt}$ ) ;

- le lot $\mathrm{A}$ reçoit le régime témoin, additionné de 0,8 p. Ioo de $\mathrm{BHT}$ (régime $\operatorname{Ra}_{2}$ );

- le lot $\mathrm{B}$ reçoit le régime témoin, adđitionné de $\mathrm{I}, 6 \mathrm{p}$. Ioo de $\mathrm{BHT}$ (régime $\mathrm{Rb}_{2}$ ). 
La composition centésimale des régimes figure sur le tableau 3. Les animaux sont pesés chaque semaine, et leur consommation alimentaire est mesurée. A l'âge de I I semaines, les animaux sont sacrifiés par saignée, après un jeûne de ${ }_{5}$ heures ; leur foie est prélevé, pesé et conservé dans l'azote liquide.

\section{TABLEAU 3}

Poulets

Composition centésimale des régimes alimentaires

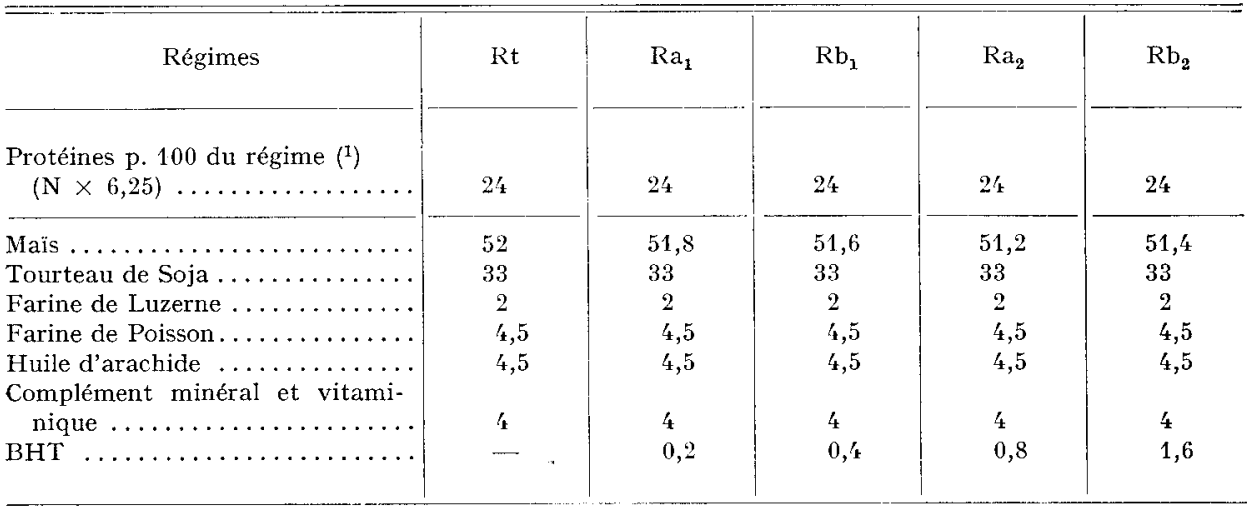

(1) Par rapport à la matière sèche.

\section{2. - Méthodes analytiques}

Les méthodes analytiques qui conduisent à la détermination des contenus hépatiques en protéines $(N \times 6,25)$ et en acides nucléiques ont déjà fait l'objet d'une description détaillée (DURAND et coll., I969).

\section{RÉSULTATS}

Expression des résultats : les quantités d'acides nucléiques, $A R N$ et $A D N$, sont exprimées en micromoles de bases ( $\mu$ M-bases) puriques et pyrimidiques ; il est aisé de transformer ces données en $\mu g$ de P-ARN ou P-ADN en les mulitpliant par 3I, ou en mg d'ARN ou d'ADN en les multipliant par 0,34 .

Certains résultats sont donnés sous forme de moyennes accompagnées de l'erreur standard. Les calculs portent sur l'analyse de variance.

$$
\text { I. - Rats }
$$

I. I. Effets de l'ingestion de BHT sur la consommation alimentaire et la vitesse de croissance. Incidence du taux protéique de la ration (tabl. 4).

Lorsque la ration contient 0,2 p. Ioo de BHT, il apparaît que l'appétit des animaux reste inférieur à celui des témoins pour les trois taux protéiques considérés. 
La consommation alimentaire est diminuée de $-8,5 \mathrm{p}$. Ioo pour $\mathrm{E}_{1}$ par rapport à $T_{1}$, de - 3,I p. Ioo pour $\mathrm{E}_{2}$ par rapport à $\mathrm{T}_{2}$, de $-5,8$ p. Ioo pour $\mathrm{E}_{3}$ par rapport à $T_{3}$. Cependant, sur l'ensemble de la période expérimentale, aussi bien pour les lots $T$

\section{TABLEAU 4}

Rats

Effets de l'ingestion de $B H T(0,2$ p. 1000 de la ration) sur la consommation alimentaire et la vitesse de croissance du Rat

\begin{tabular}{|c|c|c|c|c|c|c|c|c|c|}
\hline No des lots & $\mathrm{T}_{1}$ & $\mathrm{TR}_{\mathbf{1}}$ & $\mathrm{E}_{1}$ & $\mathrm{~T}_{2}$ & $\mathrm{TR}_{2}$ & $\mathrm{E}_{2}$ & $\mathrm{~T}_{3}$ & $\mathrm{TR}_{3}$ & $\mathrm{E}_{3}$ \\
\hline Nbre d'animaux par lot & 10 & 10 & 10 & 10 & 10 & 10 & 10 & 10 & 10 \\
\hline $\begin{array}{l}\text { Protéines } p .100 \text { de la ration } \\
(\mathrm{N} \times 6,25) \ldots \ldots \ldots \ldots \ldots\end{array}$ & 8 & 8 & 8 & 13 & 13 & 13 & 18 & 18 & 18 \\
\hline BHT p. 100 de la ration... & 0 & 0 & 0,2 & 0 & 0 & 0,2 & 0 & 0 & 0,2 \\
\hline Poids vif initial $(g) \ldots$ & 69 & 69 & 69 & 71 & 72 & 71 & 71 & 71 & 71 \\
\hline Poids vif final $(\mathrm{g}) \ldots \ldots$ & 309 & 304 & 312 & 313 & 312 & 311 & 315 & 309 & 318 \\
\hline Durée de l'expérience $(\mathrm{j})$. & 62 & 75 & 86 & 41 & 47 & 48 & 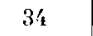 & 38 & 38 \\
\hline Gain de poids/jour (g) $\ldots$ & 3,87 & 3,13 & $2,82 *(1)$ & 5,90 & 5,10 & 5,00 & 7,18 & 6,26 & 6,50 \\
\hline Aliment ingéré $/ \mathrm{j}(\mathrm{g}) \ldots \ldots$ & 15,3 & 13,7 & 14,0 & 16,3 & 15,8 & 15,8 & 17,1 & 16,0 & 16,1 \\
\hline Indice de consommation & 3,96 & 4,36 & 4,95 & . 2,76 & 3,09 & 3,17 & 2,38 & 2,56 & 2,48 \\
\hline
\end{tabular}

(1) Les données statistiques résultent de la comparaison entre les lots expérimentaux (E) et lots témoins restreints (TR).

$* p \leqslant 0,05$.

que $\mathrm{E}_{\text {, }}$ l'appétit augmente en même temps que le taux protéique du régime : de $15,3 \mathrm{~g} / \mathrm{j}$ à $\mathrm{I} 7, \mathrm{I} \mathrm{g} / \mathrm{j}$ pour les témoins et de $\mathrm{I} 4,0 \mathrm{~g} / \mathrm{j}$ à $\mathrm{I} 6, \mathrm{I} \mathrm{g} / \mathrm{j}$ pour les expérimentaux. Toutefois, il faut noter qu'entre les lots témoins, les différences de consommation journalière deviennent surtout sensibles lorsque le poids vif des animaux dépasse $200 \mathrm{~g}$. La consommation alimentaire des lots $\mathrm{T}$ et $\mathrm{E}$, exprimée en $\mathrm{g}$ de matière sèche par jour en fonction du poids vif des animaux, est portée sur la figure I.

De même que l'appétit, la vitesse de croissance augmente avec le taux protéique du régime, tant chez les témoins que chez les expérimentaux. Cependant, dans tous les cas, la vitesse de croissance des lots $\mathrm{E}$ est inférieure à celle des lots $\mathrm{T}$ correspondants, et cela d'autant plus que le taux protéique de la ration est plus faible : soit - $27 \mathrm{p}$. Ioo pour $E_{1}$ par rapport à $T_{1},-I 5$ p. Ioo pour $E_{2}$ par rapport à $T_{2},-9,5$ p. Ioo pour $\mathrm{E}_{3}$ par rapport à $\mathrm{T}_{3}$. Dans le cas de régimes qui contiennent $\mathrm{I} 3 \mathrm{p}$. Ioo et $\mathrm{I} 8 \mathrm{p}$. Ioo de protéines, les vitesses de croissance des lots $\mathrm{E}$ et TR correspondants sont identiques et, par conséquent, la diminution de la consommation alimentaire suffirait à elle seule pour expliquer la vitesse de croissance réduite des lots $\mathrm{E}_{2}$ et $\mathrm{E}_{3}$ par rapport à $\mathrm{T}_{2}$ et $\mathrm{T}_{3}$ respectivement; par contre, lorsque le régime ne contient que $8 \mathrm{p}$. Ioo de protéines, la vitesse de croissance du lot $\mathrm{E}_{1}$ est diminuée de $\mathrm{I} 0$ p. 100 par rapport à celles du lot $T R_{1}$ : ainsi l'effet dépressif du BH'T est-il accru, ce qui laisse supposer que l'additif présente dans ces conditions des effets métaboliques différents. Les courbes de croissance des différents lots sont portées sur la figure 2. 
Pour l'ensemble des lots, l'indice de consommation (quantité d'aliment ingéré/ gain de poids) décroît en même temps qu'augmente le taux protéique du régime : soit par exemple 3,$96 ; 2,76 ; 2,38$ pour les lots $T_{1}, T_{2}, T_{3}$ respectivement.

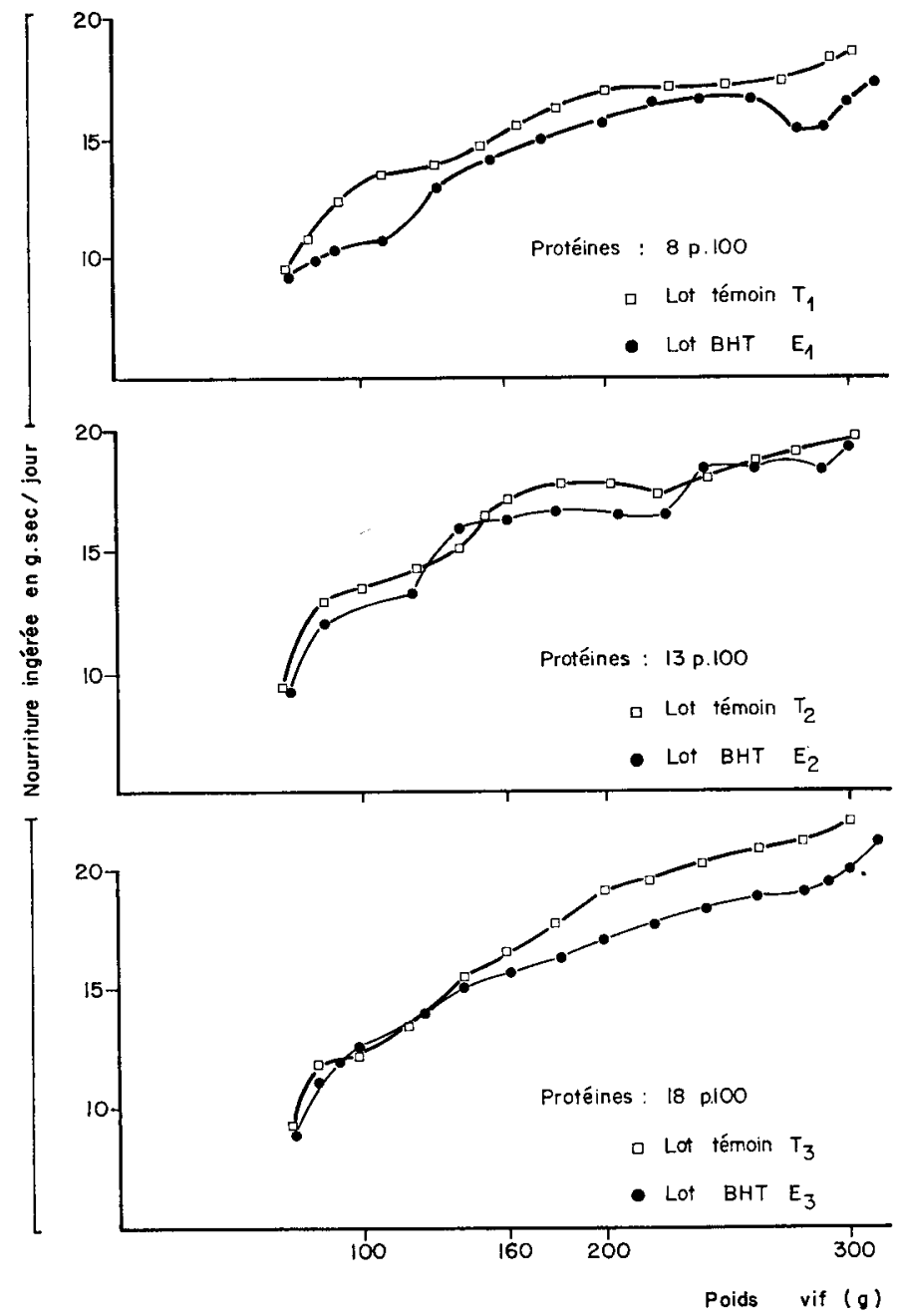

FIG. I. - Consommation alimentaire quotidienne de Rats mâles témoins et expérimentaux $(0,2 \mathrm{p}$. I oo de $\mathrm{BH}$ 'T dans la ration) en fonction de leur poids vif. Infuence du taux protéique de la ration

Pour un même régime alimentaire, l'indice de consommation des lots $\mathrm{E}$, est toujours plus élevé que celui des lots $T$ correspondants; il est équivalent à celui des lots TR lorsque les régimes contiennent $\mathbf{I} 3 \mathrm{p}$. Ioo ou $\mathbf{I} 8 \mathrm{p}$. Ioo de protéines, mais, lorsque le régime ne contient que $8 \mathrm{p}$. Ioo de protéines, il est nettement supérieur à celui du lot TR correspondant, soit 4,95 au lieu de 4,36 . 


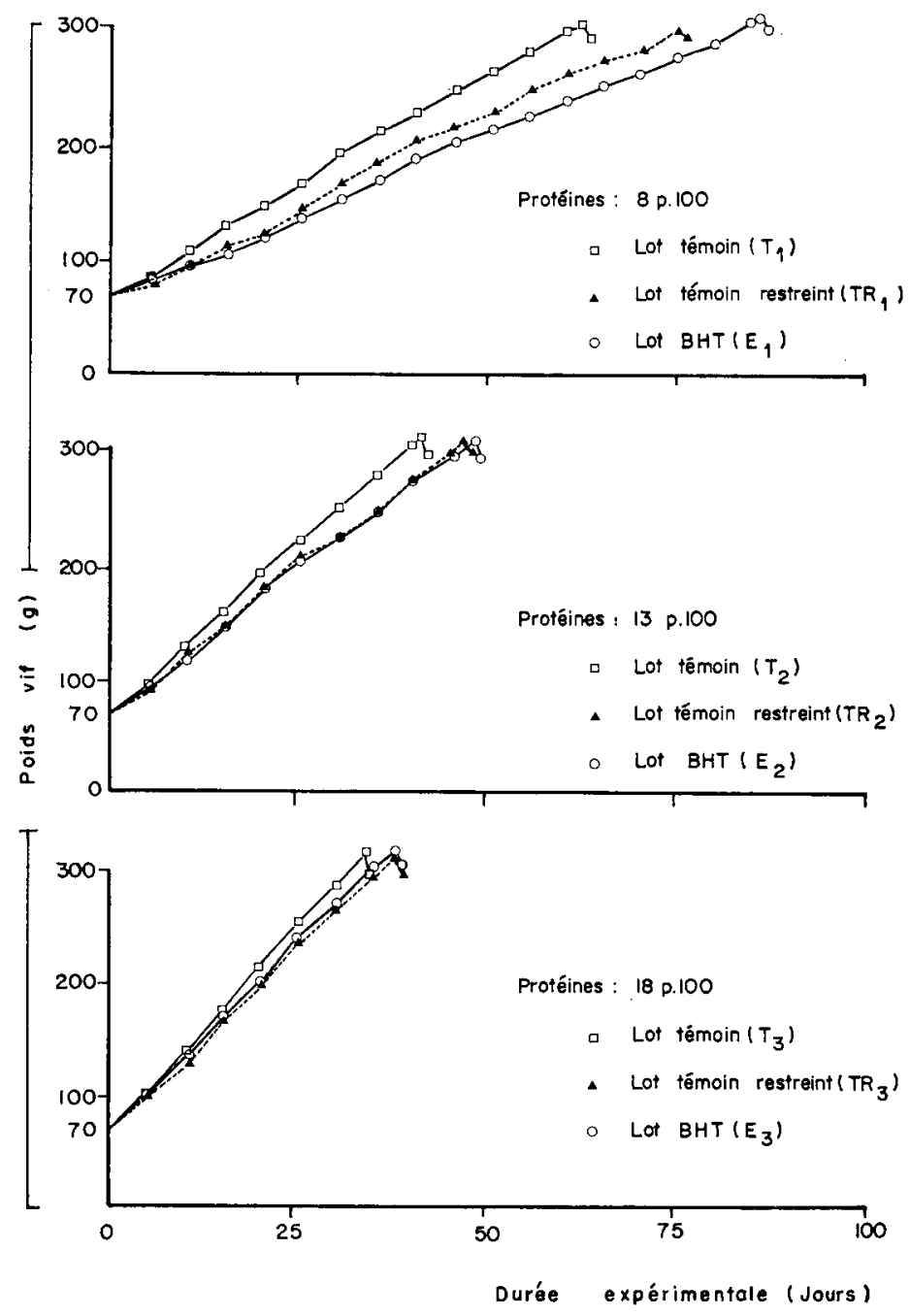

Fig. 2. - Courbes de croissance de Rats mâles témoins, témoins restreints et expérimentaux (0,2 p. Ioo de BHT dans la ration). Influence du taux protéique de la ration

I. 2. Effets de l'ingestion de BHT sur la taille du foie. Contenus en protéines et en acides nucléiques (tab1. 5).

On remarque d'abord que le poids moyen du foie passe de $7,5 \mathrm{~g}$ pour le lot $\mathrm{T}_{1}$ à $8,5 \mathrm{~g}$ pour le lot $T_{2}$ et $9,3 \mathrm{~g}$ pour le lot $\mathrm{T}_{3}$, soit des gains respectifs de + I3,5 $\mathrm{p}$. Ioo et $+24 \mathrm{p}$. Ioo pour les régimes renfermant respectivement $\mathrm{I} 3 \mathrm{p}$. Ioo et $\mathrm{I} 8 \mathrm{p}$. Ioo de protéines, par rapport au régime qui n'en contient que 8 p. Ioo; ainsi, comme l'appétit et la vitesse de croissance, le poids de l'organe est d'autant plus élevé que le taux protéique du régime est plus fort.

Pour un taux protéique déterminé du régime, on constate que le poids du foie des animaux $\mathrm{E}$ est plus élevé que celui des animaux $\mathrm{T}$ correspondants : soit 
BHT ET HYPERTROPHIE HÉPATIQUE

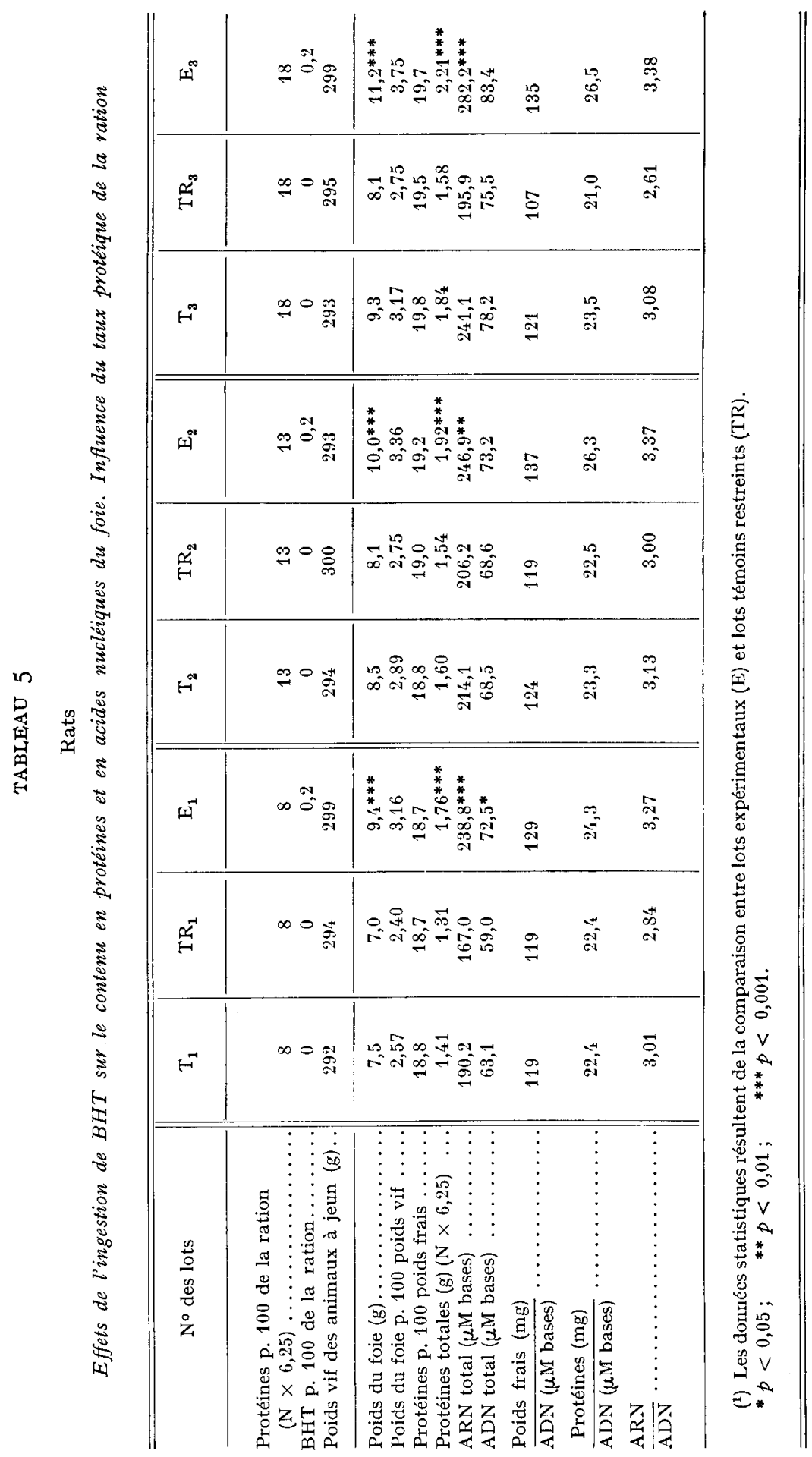


+25 p. IOO, + I8 p. IOO, + 20 p. IOO pour $\mathrm{E}_{1}, \mathrm{E}_{12}, \mathrm{E}_{3}$ par rapport à $\mathrm{T}_{1}, \mathrm{~T}_{2}, \mathrm{~T}_{3}$ respectivement. Le poids du foie des animaux TR étant légèrement inférieur à celui des animaux $T$ correspondants, la supériorité $d u$ poids des foies $\mathrm{E}$ par rapport aux foies TR est encore plus marquée; on relève ainsi des écarts de +34 p. IOO, +23 p. IOO, $+38 \mathrm{p}$. Ioo entre les lots $\mathrm{E}_{1}, \mathrm{E}_{2}, \mathrm{E}_{3}$ et $T \mathrm{TR}_{1}, \mathrm{TR}_{2}, \mathrm{TR}_{3}$ respectivement. Ces différences sont hautement significatives et paraissent indépendantes du taux protéique du régime.

Les contenus en protéines et en ARN du foie varient approximativement comme la taille de l'organe et, en conséquence, les foies hypertrophiés des animaux E contiennent significativement plus de protéines et d'ARN que ceux des animaux T et TR correspondants.

La quantité totale d'ADN hépatique augmente également en même temps que le taux protéique de la ration, à peu près proportionnellement à la taille de l'organe chez les animaux $T$ et $T R$, mais moins que proportionnellement chez les animaux $E$. Finalement, pour un taux protéique donné, le foie des animaux E contient toujours plus d'ADN que celui des animaux $T$ (soit $+I_{5}$ p. I0o, +7 p. I00, +7 p. IоO poutr $\mathrm{E}_{1}, \mathrm{E}_{12}, \mathrm{E}_{3}$ par rapport à $\mathrm{T}_{1}, \mathrm{~T}_{2}, \mathrm{~T}_{3}$ respectivement), et, à plus forte raison, que celui des animaux TR (soit +23 p. I00, +7 p. I00, + ro. p roo pour $E_{1}, E_{2}, E_{3}$ par rapport à $T R_{1}, T R_{2}, T R_{3}$ respectivement). 'Toutefois, cet accroissement n'est significatif que dans le cas où le régime ne contient que $8 \mathrm{p}$. Ioo de protéines.

Enfin, le poids frais du foie et ses contenus protéique et ribonucléique augmentant beaucoup plus fortement sous l'influence du BH'T que son contenu en $A D N$, il en résulte que les rapports poids frais/ADN, protéines/ADN et $A R N / A D N$ sont toujours plus élevés chez les animaux $\mathrm{E}$ que chez les animaux $T$ et TR.

\section{2. - Porcs}

2. I. Effets de l'ingestion de BHT sur la consommation alimentaire et la vitesse de croissance (tab1. 6).

I'addition de BHT au régime alimentaire, même à la concentration de I,2 p. Ioo, ne modifie pas l'appétit des Porcs, aussi bien mâles castrés que femelles; 1a vitesse de croissance se trouve légèrement augmentée chez les animaux qui ingèrent du BHT, mais les différences qui varient de + I p. Ioo à + II p. IoO ne sont pas significatives; du moins peut-on affirmer que l'addition de BH'T jusqu'à $\mathrm{I}, 2$ p. Ioo du régime n'a pas d'effet dépressif sur la vitesse de croissance de porcs mâles castrés et femelles. Il résulte de ce qui précède que les indices de consommation sont aussi satisfaisants, voire meilleurs, chez les animaux qui reçoivent l'antioxygène que chez les témoins.

2. 2. Effets de l'ingestion de BHT sur la taille du foie. Contenus en protéines et en acides nucléiques (tabl. 6 et 7 ).

L'ingestion de BHT provoque chez le Porc, pour les deux sexes étudiés, une hypertrophie hépatique importante. Chez les mâles castrés, celle-ci est proportionnelle à la concentration de l'additif dans le régime puisque l'augmentation du poids $\mathrm{du}$ foie est de $+24 \mathrm{p}$. Ioo et $+49,8 \mathrm{p}$. Ioo lorsque la concentration de l'antioxygène dans le régime est de $0,6 \mathrm{p}$. Ioo et $\mathrm{I}, 2 \mathrm{p}$. Ioo respectivement; chez les femelles, l'hypertrophie atteint $+4 \mathrm{I}$ p. Ioo, dès que la concentration de BHT est de 0,6 p. Ioo, 


\section{TABLEAU 6}

Porcs

Effets de l'ingestion de BHT sur la consommation alimentaire, la vitesse de croissance et le poids du foie

\begin{tabular}{|c|c|c|c|c|c|c|}
\hline $\mathrm{N}^{\circ}$ des lots & $\mathrm{TM}$ & $\mathrm{EM}_{1}$ & $\mathrm{EM}_{2}$ & TF & $\mathrm{EF}_{1}$ & $\mathrm{EF}_{2}$ \\
\hline Nombre d'animaux & 12 & 12 & 12 & 12 & 12 & 12 \\
\hline $\begin{array}{l}\text { Protéines p. } 100 \text { de la ration } \\
\qquad(\mathrm{N} \times 6,25) \ldots \ldots \ldots \ldots \ldots\end{array}$ & 16 & 16 & 16 & 16 & 16 & 16 \\
\hline BHT p. 100 de la ration.. & 0 & 0,6 & 1,2 & 0 & 0,6 & 1,2 \\
\hline $\begin{array}{l}\text { Poids vif initial }(\mathrm{kg}) \quad \ldots \ldots \ldots \ldots \\
\text { Poids vif final }(\mathrm{kg}) \ldots \ldots \ldots \ldots \\
\text { Duré de l'expérience (jour) } \ldots \ldots \\
\text { Gain de poids } / \mathrm{j}(\mathrm{g}) \ldots \ldots \ldots \ldots \ldots \\
\text { Aliment ingéré } / \mathrm{j}(\mathrm{kg}) \ldots \ldots \ldots \ldots \\
\text { Indice de consommation } \ldots \ldots \ldots\end{array}$ & $\begin{array}{l}26,1 \\
100,9 \\
107 \\
701 \\
2,40 \\
3,45\end{array}$ & $\begin{array}{c}25,4 \\
100,7 \\
97 \\
780 \\
2,46 \\
3,19\end{array}$ & $\begin{array}{l}24,6 \\
101,2 \\
108 \\
707 \\
2,28 \\
3,42\end{array}$ & $\begin{array}{c}25,0 \\
98,8 \\
114 \\
646 \\
2,08 \\
3,53\end{array}$ & $\begin{array}{l}26,1 \\
100,5 \\
105 \\
708 \\
2,33 \\
3,30\end{array}$ & $\begin{array}{l}25,9 \\
100,0 \\
107 \\
692 \\
2,24 \\
3,27\end{array}$ \\
\hline $\begin{array}{l}\text { Poids du foie }(g) \ldots \ldots \ldots \ldots \ldots \\
\text { Poids du foie p. } 100 \text { poids vif } \ldots \\
\text { Augmentation p. } 100 \ldots \ldots \ldots \ldots\end{array}$ & $\begin{array}{c}1644 \\
1,62 \\
0\end{array}$ & $\begin{array}{c}2045 * * * \\
2,03 \\
+24,4\end{array}$ & $\begin{array}{c}2463^{* * *} \\
2,43 \\
+49,8\end{array}$ & $\begin{array}{c}1509 \\
1,53 \\
0\end{array}$ & $\begin{array}{r}2129 * * * \\
2,12 \\
+41,1\end{array}$ & $\begin{array}{r}2228^{* * *} \\
2,23 \\
+47,6\end{array}$ \\
\hline
\end{tabular}

$* p<0,05 ; \quad * * p<0,01 ; \quad * * * p<0,001$

TABL,EAU 7

Porcs

Effet de l'ingestion de BHT sur le contenu en protéines et en acides nucléiques du foie

\begin{tabular}{|c|c|c|c|c|}
\hline No des lots & TM & $\mathrm{EM}_{2}$ & TF & $\mathrm{EF}_{2}$ \\
\hline Nombre d'animaux & 9 & 8 & 6 & 6 \\
\hline $\begin{array}{l}\text { BHT p. } 100 \text { de la ration } \ldots \ldots \ldots \ldots \\
\text { Poids vif des animaux à jeun }(g) \ldots \ldots\end{array}$ & $\begin{array}{c}0 \\
100,4\end{array}$ & $\begin{array}{r}1,2 \\
100,9\end{array}$ & $\begin{array}{l}0 \\
99,5\end{array}$ & $\begin{array}{r}1,2 \\
100,0\end{array}$ \\
\hline $\begin{array}{l}\text { Poids du foie }(g) \ldots \ldots \ldots \ldots \ldots \\
\text { Poids du foie p. } 100 \text { poids vif } \ldots \ldots \\
\text { Protéines p. } 100 \text { poids frais } \ldots \ldots \ldots \\
\text { Proteines totales }(g)(\mathrm{N} \times 6,25) \ldots \ldots \\
\text { ARN total }(\mu \mathrm{M} \text {-bases) } \ldots \ldots \ldots \ldots \ldots \\
\text { ADN total ( } \mu \text { M-bases) } \ldots \ldots \ldots \ldots\end{array}$ & $\begin{array}{rl}1572 & \\
1,56 \\
19,1 \\
& 300 \\
24 & 450 \\
10 & 836\end{array}$ & $\begin{array}{r}2406^{* * *} \\
2,38 \\
18,6^{*} \\
449^{* *} \\
35149^{* * *} \\
15032^{* * *}\end{array}$ & $\begin{aligned} 1481 \\
1,48 \\
18,0 \\
268 \\
22414 \\
10635\end{aligned}$ & $\begin{array}{r}2145^{* *} \\
2,14 \\
18,2 \\
391^{* * *} \\
30908^{* * *} \\
12764^{* *}\end{array}$ \\
\hline$\frac{\text { Poids frais }(\mathrm{g})}{\text { ADN (mM-bases) }}$ & 146 & 162 & 140 & 168 \\
\hline$\frac{\text { Protéines (g) }}{\text { ADN mM-bases) }}$ & 27,7 & 29,9 & 25,2 & 30,6 \\
\hline$\frac{\mathrm{ARN}}{\mathrm{ADN}} \ldots \ldots \ldots \ldots \ldots \ldots \ldots \ldots$ & 2,26 & 2,35 & 2,11 & 2,42 \\
\hline
\end{tabular}

$* p<0,05 ; \quad * * p<0,01 ; \quad * * * p<0,001$. 
et n'excède pas +48 p. Ioo, lorsque le régime renferme I,2 p. Ioo de l'additif. Il apparaît, dès lors, que mâles castrés et femelles réagissent différemment à l'ingestion de l'antioxygène.

Les contenus en protéines et en acides nucléiques ne sont mesurés que sur une partie des Porcs, castrats et femelles, appartenant aux lots témoins et aux lots expérimentaux dont la ration contient I,2 p. Ioo de BH'T (tabl. 7).

La teneur du foie en protéines, qui se situe entre I8 p. Ioo et I9 $\mathrm{p}$. Ioo, ne dépend pas du sexe et n'est pas modifiée par l'introduction de BH'T dans le régime alimentaire. Il en résulte que le contenu protéique de l'organe varie approximativement comme son poids et que, sous l'effet de l'antioxygène, il présente des augmentations de +50 p. Ioo et +46 p. Ioo chez les castrats et les femelles respectivement. Les foies des témoins mâles castrés contiennent davantage d'ARN que ceux des témoins femelles ( +9 p. Ioo); cette différence n'est pas significative. Dans les organes hypertrophiés, le capital en ARN est augmenté de $+44 \mathrm{p}$. Ioo chez les castrats et de +37 p. Ioo chez les femelles: on constate donc une augmentaticn plus accusée chez les castrats ; toutefois, dans les deux cas, l'augmentation du contenu ribonucléique du foie reste inférieure à l'accroissement du poids frais et du contenu protéique de 1'organe, contrairement à ce que l'on observe chez le Rat.

Chez les témoins, la quantité d'ADN hépatique n'est pas différente suivant le sexe. Chez les animaux qui ingèrent $\mathrm{du} B \mathrm{BH}^{\prime} \mathrm{T}$, on relève une augmentation très marquée de 1'ADN hépatique, soit $+39 \mathrm{p}$. Ioo pour les castrats et $+20 \mathrm{p}$. Ioo pour les femelles : les castrats révèlent sur ce point une plus grande sensibilité à l'additif.

Le rapport poids frais/ADN est accru de + ir p. Ioo chez les castrats et de +20 p. Ioo chez les femelles soumis au BHT; le rapport protéines/ADN subit des variations très voisines, soit $+8 \mathrm{p}$. Ioo et $+20 \mathrm{p}$. Ioo pour les castrats et les femelles respectivement. Quant au rapport $A R N / A D N$, il apparaît, avec une valeur de 2,26 contre 2, II, un peu plus élevé chez les témoins mâles castrés que chez les femelles; sous l'effet du traitement par le BH'T, ce rapport augmente plus chez les femelles, où il passe de 2, II à 2,42 , que chez les castrats où, en passant seulement de 2,26 à 2,35 , il ne varie pas sensiblement.

\section{3. - Poulets}

\section{I. Effets de l'ingestion de BHT sur la consommation alimentaire et la vitesse de crois- sance (tabl. 8).}

Il ressort clairement des résultats que l'addition de BH'T aux concentrations de 0,2 p. Ioo et 0,4 p. Ioo n'a aucun effet ni sur l'appétit, ni sur la vitesse de croissance de Poulets mâles âgés de 5 à 9 semaines.

De l'âge de 9 semaines à celui de I I semaines, lorsque les concentrations de l'antioxygène sont quadruplées dans les deux régimes, on constate que la concentration de 0,8 p. Ioo est également sans effet sur l'appétit et sur la vitesse de croissance. Par contre, l'ingestion d'un régime contenant $I, 6$ p. Ioo de BHT, bien qu'il ne provoque qu'une légère diminution de l'appétit, soit - 7,5 p. Ioo, entraîne une chute spectaculaire de la vitesse de croissance qui tombe de 43-44 $\mathrm{g} / \mathrm{jour}$ chez les témoins à $\mathrm{I} 9,4 \mathrm{~g} /$ jour chez les expérimentaux.

Il en résulte une altération considérable de l'indice de consommation qui 
atteint 7,72 chez les Poulets expérimentaux du lot B, alors qu'il est de 3,66 chez le lot témoins. On remarque également chez les animaux du lot $B$ une augmentation importante de la teneur en eau des fèces : 25 p. Ioo au lieu de I5 p. Ioo pour les autres lots.

\section{TABLEAU 8}

Poulets

Effets de l'ingestion de BHT sur la consommation alimentaire, la vitesse de croissance et le poids du foie

\begin{tabular}{|c|c|c|c|c|c|c|}
\hline No des lots & $\mathrm{T}$ & A & B & $\mathrm{T}$ & A & B \\
\hline Nombre d'animaux & 12 & 12 & 12 & 12 & 12 & 12 \\
\hline Protéines p. 100 de la ration & 24 & 24 & 24 & 24 & 24 & 24 \\
\hline BHT p. 100 de la ration ... & 0 & 0,2 & $0,{ }^{\prime}$ & 0 & 0,8 & 1,6 \\
\hline Age (semaines) & $5 \rightarrow 9$ & $5 \rightarrow 9$ & $5 \rightarrow 9$ & $9 \rightarrow 11$ & $9 \rightarrow 11$ & $9 \rightarrow 11$ \\
\hline $\begin{array}{l}\text { Poids vif }(\mathrm{g}) \ldots \ldots \ldots \ldots \\
\text { Gain de poids vif } / \mathrm{j}(\mathrm{g}) \ldots \ldots \\
\text { Consommation alim. } \ldots \mathrm{j}(\mathrm{g}) . \\
\text { Indice de consommation... }\end{array}$ & $\left|\begin{array}{c}9 / 49 \rightarrow 2460 \\
54,0 \\
131,8 \\
2,14\end{array}\right|$ & $\mid \begin{array}{c}947 \rightarrow 24_{1} 06 \\
52,1 \\
128,8 \\
2,47\end{array}$ & $\mid \begin{array}{c}947 \rightarrow 2432 \\
53,0 \\
132,0 \\
2,49\end{array}$ & \begin{tabular}{|c|}
$2460 \rightarrow 3075$ \\
43,9 \\
161,0 \\
3,66
\end{tabular} & $\mid \begin{array}{c}2406 \rightarrow 3010 \\
43,1 \\
159,6 \\
3,70\end{array}$ & $\begin{array}{c}2432 \rightarrow 2704^{* *} \\
19,4 \\
149,7 \\
7,72\end{array}$ \\
\hline Poids du foie $(g) \ldots \ldots \ldots$ & & & & 40,4 & $45,8^{*}$ & $55,8^{* *}$ \\
\hline $\begin{array}{l}\text { P. } 100 \text { d'augmentation.... } \\
\text { Poids du foiep. } 100 \text { poids vif } \\
\text { BHT ingéré } / \mathrm{kg} / \mathrm{j}(\mathrm{mg})\end{array}$ & 0 & 154 & 312 & $\begin{array}{l}1,31 \\
0\end{array}$ & $\begin{array}{c}+13,3 \\
1,55 \\
472\end{array}$ & $\begin{array}{c}+38,1 \\
2,06 \\
933\end{array}$ \\
\hline
\end{tabular}

${ }^{*} p<0,05 ; \quad * * p<0,01$.

Ainsi, si l'on s'en rapporte seulement à l'aspect extérieur, à l'appétit et à la vitesse de croissance, le Poulet tolère parfaitement un régime alimentaire contenant o,8 p. Ioo de $\mathrm{BH}^{\prime} \mathrm{T}$; en revanche, le taux de $\mathrm{I}, 6 \mathrm{p}$. Ioo limite fortement la vitesse de croissance, ce qui peut être un symptôme du dépassement du seuil de toxicité.

Si l'on considère la quantité de $\mathrm{BH}$ T $(\mathrm{mg})$ ingérée par $\mathrm{kg}$ de poids vif/jour, il apparaît que le seuil de tolérance à l'additif du Poulet en croissance se situe entre $500 \mathrm{mg} / \mathrm{kg} /$ jour et $900 \mathrm{mg} / \mathrm{kg} / \mathrm{jour}$, lorsque l'antioxygène est inclus dans un régime renfermant 24 p. Ioo de protéines.

3. 2. Effets de l'ingestion de BHT sur la taille du foie. Contenus en protéines et en acides nucléiques (tabl. 9).

Chez les animaux sacrifiés à l'âge de II semaines, on constate une hypertrophie du foie, légère mais significative ( $+\mathrm{I} 3,3$ p. Ioo; $p<0,05)$, chez les animaux qui reçoivent $0,8 \mathrm{p}$. Ioo de $\mathrm{BH}$ T, et une hypertrophie importante $(+38$, I p. Ioo ; $p<0,00$ I) chez les animaux qui reçoivent I,6 p. Ioo de BH'T. L'organe représente 
I,3I p. Ioo du poids vif d'un animal témoin et $2,06 \mathrm{p}$. Ioo du poids vif d'un animal $\mathrm{du}$ lot $\mathrm{B}$.

Les dosages de protéines $(N \times 6,25)$, de RNA et DNA sont effectués pour chaque lot sur six foies choisis au hasard. Les résultats indiquent que la concentration des protéines dans l'organe n'est pas modifiée par l'ingestion de l'antioxygène et que, par conséquent, le contenu protéique total des foies évolue parallèlement à l'hypertrophie; il en va de même pour le RNA, de sorte que le rapport protéines/ RNA reste inchangé.

\section{TABLEAU 9}

Poulets

Effets de l'ingestion de BHT sur les contenus en protéines en acides nucléiques du foie

\begin{tabular}{|c|c|c|c|}
\hline Lots & $\mathrm{T}$ & $A$ & B \\
\hline P. $100 \mathrm{BHT}$ dans la ration ...... & 0 & 0,8 & 1,6 \\
\hline Nombre d'animaux $\ldots \ldots \ldots \ldots$ & 6 & 6 & 6 \\
\hline Poids vif poulet $(g) \ldots \ldots \ldots \ldots \ldots$ & $3156 \pm 120,5$ & $3021 \pm 121,3$ & $2718 \pm 57,0^{* *}$ \\
\hline $\begin{array}{l}\text { Poids du foie }(g) \ldots \ldots \ldots \ldots \ldots \\
\text { P. } 100 \text { d'augmentation } \ldots \ldots \ldots \ldots \\
\text { Poids frais p. } 100 \text { poids vif } \ldots \ldots \ldots \ldots \\
\text { Protéines totales (g) } \ldots \ldots \ldots \ldots \ldots \\
\text { RNA total }(\mu M \text { bases) } \ldots \ldots \ldots \ldots \ldots \\
\text { DNA total ( } \mu \text { M bases) } \ldots \ldots \ldots \ldots \ldots\end{array}$ & $\begin{array}{l}40,6 \pm 3,1 \\
1,29 \\
7,57 \\
968 \\
432\end{array}$ & $\begin{array}{l}48,2 \pm 2,1^{*} \\
+18,7 \\
1,60 \\
8,73^{*} \\
1156^{*} \\
460 \mathrm{NS}\end{array}$ & $\begin{array}{c}54,3 \pm 2,6^{* *} \\
+33,7 \\
2,00 \\
9,61 * * \\
1207^{* *} \\
453 \text { NS }\end{array}$ \\
\hline$\frac{\text { Poids frais }(\mathrm{mg})}{\text { DNA }(\mu \mathrm{M} \text { bases })} \ldots \ldots \ldots \ldots \ldots$ & $9 / 4,0$ & $10^{\prime}, 8$ & 119,9 \\
\hline$\frac{\text { Protéines }(\mathrm{mg})}{\text { DNA }(\mu \mathrm{M} \text { bases })} \ldots \ldots \ldots \ldots$ & 17,5 & 19,0 & 21,2 \\
\hline$\frac{\text { Protéines }(\mathrm{mg})}{\text { RNA }(\mu \mathrm{M} \text { bases })}$ & $7,8:$ & 7,55 & 7,96 \\
\hline$\frac{\mathrm{RNA}}{\mathrm{I} \mathrm{NA}}$ & 2,25 & 2,51 & 2,66 \\
\hline
\end{tabular}

$* p<0,05 ; \quad * * p<0,01 ; \quad * * * p<0,001$

Au contraire, la concentration d'ADN est diminuée, d'une façon inversement proportionnelle à l'hypertrophie, si bien que la quantité totale d'ADN n'est pas modifiée significativement, même chez les animaux dont le régime contient I, 6 p. Ioo de BHT.

Compte tenu de cela, les rapports poids frais/ADN, protéines/ADN et ARN/ADN sont augmentés proportionnellement à l'hypertrophie de l'organe. 


\title{
DISCUSSION
}

\author{
Rats
}

\section{Appétit et vitesse de croissance.}

Les résultats de ce travail montrent que l'ingestion de $\mathrm{BH} T$, incorporé à raison de 0,2 p. Ioo dans des régimes alimentaires équilibrés contenant de 8 p. IOO à I 8 p. Ioo de protéines, déprime systématiquement 1'appétit et la vitesse de croissance, et détériore l'indice de consommation de Rats mâles dont le poids passe de $70 \mathrm{~g}$ à $300 \mathrm{~g}$. Cependant, les effets de l'additif sur ces critères sont d'autant moins marqués que le taux protéique est plus élevé; par ailleurs, si le taux protéique de la ration est optimal ( 8 p. Ioo) ou sub-optimal (I3 p. Ioo), les animaux qui reçoivent 0,2 p. Ioo de BHT présentent des vitesses de croissance et des indices de consommation équivalents à ceux des témoins dont la consommation alimentaire quotidienne est alignée au même niveau (témoins restreints). Sans plus ample investigation, on pourrait ainsi penser que le seul effet du BHT est de restreindre la consommation alimentaire et que les animaux BHT et témoins restreints sont identiques; en fait, il n'en est rien car les animaux BH'T sont significativement plus maigres que les témoins restreints correspondants (résultats à paraître), ce qui confirme des données précédentes (PAsCAL et Durand, I970; PAScal, I97r). De plus, l'ingestion de BHT est toujours accompagnée d'une hypertrophie hépatique, tandis que les témoins restreints présentent une hypotrophie hépatique, souvent légère, mais systématique.

Lorsque le taux protéique du régime est insuffisant, les effets dépressifs du BHT sont accrus et les deux critères - vitesse de croissance et indice de consommation deviennent alors moins satisfaisants chez les Rats BHT que chez les témoins restreints correspondants. Les corps des uns et des autres renfermant des quantités de protéines comparables, il apparaît que l'ingestion de BHT est suivie d'un certain gaspillage des protéines alimentaires qui se situe, selon toute vraisemblance, au plan de l'utilisation métabolique, puisque PASCAL et TERroine (I972) et Durand et PASCAL (résultats non publiés) ont montré que la présence de BHT dans la ration n'exerce aucune influence sur la digestibilité des protéines.

L'effet de l'ingestion de BHT sur l'appétit et la vitesse de croissance a été assez fréquemment observé chez le Rat au cours des vingt dernières années. DEICHMANN et coll. (I955), avec des régimes contenant o,8 p. Ioo et I p. Ioo de BHT constatent une diminution d'appétit de $16 \mathrm{p}$. Ioo et des diminutions de vitesse de croissance de $4^{\circ} \mathrm{p}$. Ioo et $78 \mathrm{p}$. Ioo. BRown et coll. (r959) montrent que le BH'T incorporé à la concentration de $0, I$ p. Ioo dans un régime contenant Io p. Ioo de lard n'a pas d'effet sur la vitesse de croissance, tandis qu'il la réduit de moitié environ lorsque sa concentration est portée à 0,5 p. IOo. GAUNT et coll. (I965 a) ne trouvent pas d'effet sur la vitesse de croissance pour une concentration de BH'T de o, I p. roo. Frawley et coll. (I965) font, pour $0, I$ p. Ioo, la même observation, tandis qu'à la concentration de $0,3 \mathrm{p}$. Ioo, le poids des animaux est réduit de $5 \mathrm{p}$. Ioo en moyenne. Pascal et al. (I970) constatent que l'addition de BHT au taux de $0, \mathrm{I}$ p. Ioo dans un régime contenant $\mathrm{I}_{3} \mathrm{p}$. Ioo de protéines diminue la consommation alimentaire de $-5,5 \mathrm{p}$. Ioo 
et la vitesse de croissance de $-8,3 \mathrm{p}$. Ioo, mais ces données sont à la limite de la signification statistique ; lorsque le taux de BH'T est porté à 0,5 p. Ioo, la consommation alimentaire quotidienne est diminuée de $-\mathrm{I} 8,5 \mathrm{p}$. Ioo et la vitesse de croissance de - 40 p. IOo, ces différences étant hautement significatives ; l'indice de consommation n'est pratiquement pas modifié pour le taux de $0, \mathrm{I}$ p. Ioo, mais considérablement augmenté pour le taux de 0,5 p. IOo. DURANd et Pascal. (I973) observent que chez des Rats mâles adultes, auxquels est distribué un régime contenant $13 \mathrm{p}$. Ioo de protéines et du BHT dont la concentration augmente de $0, \mathbf{I}$ p. IOO à 2,I p. IOO, l'appétit marque, dès $0, \mathrm{I}$ p. Ioo, une légère diminution ; celle-ci s'aggrave lentement lorsque le taux de l'additif augmente, et devient dramatique à partir de I,3 p. Ioo. Par contre, lorsque la concentration protéique du régime est portée à $26 \mathrm{p}$. Ioo, les animaux peuvent tolérer 2,I p. Ioo de BH'T. Ainsi, alors que l'organisme du Rat mâle adulte ne peut supporter plus de $300 \mathrm{mg}$ de $\mathrm{BH} / \mathrm{T} / \mathrm{kg}$ de poids vif $/$ jour lorsque la ration contient I $3 \mathrm{p}$. Ioo de protéines, il peut tolérer jusqu'à $630 \mathrm{mg} / \mathrm{kg} / \mathrm{jour}$ lorsque le régime renferme $26 \mathrm{p}$. Ioo de protéines. Ces données sont à rapprocher des résultats de GontzFa et coll. (I964-I968), Garner et McLEan (I969), March et coll. (I968) qui montrent que la toxicité de nombreuses drogues est diminuée lorsque le taux protéique du régime augmente. Un apport supplémentaire de protéines, qui favorise la formation de nombreuses enzymes, permet peut-être une synthèse accrue de la BHT-oxydase hépatique, principal agent du métabolisme du BHT dans l'organisme (GILBERT et GolBERG, I967). Il faut toutefois remarquer que le Rat impubère peut supporter, relativement à son poids vif, des doses très supérieures à celles que tolère l'adulte (PASCAI, et coll., I970).

Seuls et contrairement au autres auteurs, SPORN et ScHoBESH (I96I) signalent une certaine stimulation de la croissance che $z$ des rats qui reçoivent un régime renfermant 0,2 p. Ioo de BHT.

En résumé, on peut affirmer à l'heure actuelle que chez le Rat recevant un régime normalement équilibré, contenant de $\mathrm{I} 3 \mathrm{p}$. Ioo à $\mathrm{I} 8 \mathrm{p}$. Ioo de protéines, la concentration de o,I p. IOO de BHT dans le régime est une concentration seuil, au-delà de laquelle on constate un effet dépressif de l'additif sur l'appétit, la vitesse de croissance et l'efficacité alimentaire. Mais d'une manière générale, la concentration " seuil " dépend au premier chef de la concentration en protéines du régime alimentaire.

\section{BHT et hypertrophie hépatique.}

I. Lorsque l'on considère des animaux de même poids, il ressort des résultats du présent travail les éléments suivants :

a) Chez les témoins, le poids des foies des animaux est d'autant plus important et contient d'autant plus de protéines, d'ARN et d'ADN, que le régime alimentaire est plus riche en protéines, ce qui est en accord avec les conclusions de précédents travaux (Sugahara et coll., I969 ; DURAND, I973) ; toutefois, les concentrations de ces divers composés n'étant pas modifiées, les rapports poids frais/ADN et protéines/ADN, utilisés habituellement comme critères de la taille des cellules, restent inchangés. Mais on ne peut pas en conclure que l'augmentation du contenu hépatique en $A D N$, parallèle à l'augmentation du poids de l'organe, est due à l'hyperplasie ; il est probable, en effet, que le taux de polyploïde des noyaux des hépatocytes, 
sensible aux insuffisances nutritionnelles (NADAL et ZAJDELA, I966), s'accroisse en même temps que le taux de protéines du régime se rapproche de l'optimum;

b) L'addition de $\mathrm{BH}$ 'T au régime, à la concentration de o,2 p. Ioo, provoque une hypertrophie hépatique variant de 23 p. Ioo à $38 \mathrm{p}$. Ioo, indépendamment du taux protéique du régime ; on sait par ailleurs que l'effet hypertrophiant de l'additif est déjà net lorsque sa concentration atteint $0, \mathrm{I}$ p. Ioo (PASCAL et coll., I970), et semble se manifester chez les deux sexes à partir de 0,05 p. IOO (PAscal et TERroine I $969 b)$; cette concentration correspond à 1'ingestion de doses de BH'T variant de $70 \mathrm{mg} / \mathrm{j} / \mathrm{kg}$ à $33 \mathrm{mg} / \mathrm{j} / \mathrm{kg}$ pour des Rats mâles dont le poids vif passe de $70 \mathrm{~g}$ à $300 \mathrm{~g}$; ces données sont très comparables à celles fournies par GILBERT et GoLBERG (I965). Les contenus en protéines et en ARN augmentent proportionnellement à la taille du foie, ce qui confirme les résultats d'un précédent travail (PAScAL et coll., 1970) ; la synthèse d'ADN est moins stimulée puisque, à poids égal d'animal, la quantité d'ADN hépatique des Rats BHT n'est pas significativement différente de celle des témoins et témoins restreints, lorsque les régimes contiennent $13 \mathrm{p}$. Ioo et I8p. I00 de protéines. Cependant, lorsque le régime ne contient que $8 \mathrm{p}$. Ioo de protéines, la quantité de DNA hépatique est significativement augmentée par rapport à celle des témoins restreints.

\section{TABLEAU IO}

Rats en croissance

Effets de l'ingestion de BHT sur les quantités d'ADN

d'ARN et de protéines accumulées par jour dans le foie des rats témoins (T), témoins restreints (TR), ou expérimentaux (E). Infuence du taux protéique de la ration

\begin{tabular}{|c|c|c|c|c|c|c|}
\hline No du lot & $\mathrm{T}$ & TR & $\mathrm{E}$ & & & \\
\hline BHT p.100 de la ration & 0 & 0 & 0,2 & & & \\
\hline Protéines $(\%)-\downarrow$ & & & & & & \\
\hline ADN $/ j$ ( $\mu$ M-bases) $\left\{\begin{array}{r}8 \ldots \\
13 \ldots \\
18 \ldots\end{array}\right.$ & $\begin{array}{l}0,62 \\
1,07 \\
1,57\end{array}$ & $\begin{array}{l}0,46 \\
0,93 \\
1,34\end{array}$ & $\begin{array}{l}0,56 \\
1,01 \\
1,54\end{array}$ & $\begin{array}{r}9,7 \\
-\quad 5,6 \\
-\quad 1,9\end{array}$ & $\begin{array}{r}+21,7 \\
+\quad 8,6 \\
+\quad 14,9\end{array}$ & $\begin{array}{r}-25,8 \\
-13,1 \\
-14,6\end{array}$ \\
\hline $\operatorname{ARN} / \mathrm{j}(u \mathrm{M}-$ bases $)\left\{\begin{array}{r}8 \ldots \\
13 \ldots \\
18 \ldots\end{array}\right.$ & $\begin{array}{l}1,83 \\
3,36 \\
4,84\end{array}$ & $\begin{array}{l}1,21 \\
2,76 \\
3,1 / 4\end{array}$ & $\begin{array}{l}1,89 \\
3,55 \\
5,41\end{array}$ & $\begin{array}{l}+\quad 3,2 \\
+\quad 5,6 \\
+\quad 11,7\end{array}$ & $\begin{array}{l}+56,2 \\
+28,6 \\
+72,3\end{array}$ & $\begin{array}{r}33,9 \\
-17,8 \\
-35,1\end{array}$ \\
\hline Protéines $/ \mathrm{j}(\mathrm{mg})\left\{\begin{array}{r}8 \\
13 \ldots \\
18 \ldots\end{array}\right.$ & $\begin{array}{l}15,8 \\
28,5 \\
41,5\end{array}$ & $\begin{array}{l}11,7 \\
23,6 \\
30,3\end{array}$ & $\begin{array}{l}15,5 \\
31,0 \\
46,8\end{array}$ & $\begin{array}{r}1,9 \\
+\quad 8,8 \\
+\quad 12,8\end{array}$ & $\begin{array}{l}+32,5 \\
+31,3 \\
+\quad 51,1\end{array}$ & $\begin{array}{r}25,9 \\
-17,2 \\
-26,9\end{array}$ \\
\hline
\end{tabular}

2. Mais considérons maintenant les quantités moyennes d'ADN, d'ARN et de protéines accumulées par jour chez les différents lots, sachant qu'au début de l'expérience le foie des rats (70 $\mathrm{g}, 4$ semaines) contient approximativement : $24,7 \mu \mathrm{M}-$ bases d'ADN; $76,5 \mu \mathrm{M}$-bases d'ARN; $0,43 \mathrm{~g}$ de protéines $(\mathrm{N} \times 6,25)$ (DURAND et PeNot, I970). Il apparaît (tabl. Io) que les animaux BHT accumulent par jour davantage d'ADN que les témoins restreints, mais moins que les animaux témoins 
nourris ad libitum : il en résulte que le BH'T a bien une action stimulante sur la synthèse d'ADN, mais qui ne compense pas, ou parvient tout juste à compenser l'effet dépressif que manifeste, sur cette accumulation, la restriction qu'il provoque par ailleurs (DURAND et coll., I967 ; DURAND, I973). Finalement, malgré les apparences, la synthèse d'ADN est moins forte chez les animaux BHT que chez les témoins nourris ad libitum, et cette infériorité tend à disparaître lorsque le taux protéique de la ration augmente.

L'examen des quantités moyennes d'ARN et de protéines accumulées par jour montre que ces quantités sont plus élevées chez les animaux BHT que chez les témoins restreints et qu'elles sont également plus élevées que chez les témoins nourris ad libitum, contrairement à ce que l'on constate pour l'ADN. Ces phénomènes sont d'autant plus accentués que le taux protéique du régime est plus élevé.

On parvient finalement aux conclusions suivantes:

Chez le Rat, l'administration de BHT dans le régime en un temps donné;

a) N'accroît pas le contenu hépatique en $\mathrm{ADN}$ par rapport à des témoins nourris ad libitum. Il ne peut que le diminuer lorsque le taux de l'additif est trop élevé par rapport au taux protéique de la ration. Ceci est en accord avec les résultats de PASCAL et coll. (I970), qui montrent que les foies de Rats recevant du BH'T au taux de $0, \mathrm{I}$ p. Ioo et 0,5 p. Ioo, ajouté à un régime contenant I3 p. Ioo de protéines, renferment moins d'ADN que les foies de témoins de même âge nourris ad libitum :

b) Peut accroître l'accumulation de protéines et d'ARN, ceci d'autant plus que le taux protéique du régime est plus élevé.

Il en résulte qu'à âge égal on peut émettre l'hypothèse que l'hypertrophie du foie devient d'autant plus forte que le taux protéique de la ration s'élève.

Certains auteurs (LANE et LIEBER, I967; KERR et coll., I966) affirment que l'hypertrophie hépatique chez le Rat est accompagnée d'un nombre accru de mitoses et d'une incorporation augmentée de thymidine tritiée ; ils concluent de leurs travaux que l'hypertrophie du foie s'accompagne d'une certaine stimulation de l'hyperplasie. $\mathrm{Si}$ ces auteurs comparent leurs animaux expérimentaux à des témoins restreints, leurs résultats ne sont pas en contradiction avec les nôtres ; s'ils établissent la comparaison avec des animaux nourris ad libitum, l'augmentation modérée du nombre de mitoses pourrait s'expliquer dans l'hypothèse où le BHT limiterait la polyploìdie ; mais s'il en est ainsi, l'augmentation de l'incorporation de thymidine radioactive signalée par KERR et coll. paraît surprenante, à moins qu'il ne s'agisse d'une accélération du turnover du nucléotide. Quoi qu'il en soit, ces auteurs reconnaissent par ailleurs une forte augmentation de la dimension des hépatocytes qui permet d'expliquer, en grande partie, 1'hypertrophie hépatique constatée.

\section{Porcs}

\section{Appétit et vitesse de croissance.}

Nos résultats indiquent qu'entre $25 \mathrm{~kg}$ et Ioo $\mathrm{kg}$, l'appétit et la vitesse de croissance de Porcs mâles castrés et femelles ne sont pas modifiés, même si 1'on ajoute jusqu'à $I, 2$ p. Ioo de BHT dans leur régime alimentaire contenant I9 p. roo de protéines.

Précédemment, Desmoulan et coll. (I972) ne constatent aucun effet de l'additif 
sur l'appétit, la vitesse de croissance et l'indice de consommation chez des Porcs mâles castrés recevant, depuis le poids de $25 \mathrm{~kg}$ jusqu'à celui de Ioo $\mathrm{kg}$, des régimes alimentaires renfermant I9 p. Ioo de protéines et jusqu'à 0,8 p. Ioo de BHT. Chez des Porcs mâles entiers dont le poids passe de $20 \mathrm{~kg}$ à I $20-\mathrm{I} 4 \mathrm{o} \mathrm{kg}$, et recevant I9 $\mathrm{p}$. IoO de protéines, Desmoulin et coll. (1973) constatent que l'addition de BHT au régime, à la concentration de 0,4 p. Ioo, reste sans effet sur l'appétit et la vitesse de croissance des animaux, tandis qu'à la concentration de 0,8 p. roo, l'antioxygène semble provoquer une légère diminution de ces facteurs : peut-être s'agit-il là de la concentration au-delà de laquelle l'antioxygène agirait sur l'appétit et la vitesse de croissance du Porc mâle entier, mais des vérifications sont nécessaires.

Quoi qu'il en soit, on constate que le Rat mâle tolère moins bien le BH'T que le Porc, femelle ou mâle castré, puisque le premier commence à réduire sa consommation alimentaire dès que le taux de BHT dans sa ration atteint $0, \mathrm{I}$ p. Ioo, tandis que le second peut consommer une ration contenant $\mathrm{I}, 2$ p. Ioo de BH'T sans répercussion ni sur l'appétit, ni sur la vitesse de croissance; chez le Porc, dont le poids passe de $25 \mathrm{~kg}$ à $100 \mathrm{~kg}$, cela correspond à des ingestions de BH T variant de $800 \mathrm{mg} / \mathrm{kg} / \mathrm{j}$ à 400 $\mathrm{mg} / \mathrm{kg} / \mathrm{j}$. Peut-être la BH'T-oxydase est-elle plus active chez le Porc que chez le Rat ?

\section{BHT et hypertrophie hépatique.}

DesMoulin et coll. (I972) montrent que les Porcs mâles castrés abattus à Ioo kg après avoir reçu de $25 \mathrm{~kg}$ à Ioo $\mathrm{kg}$, un régime renfermant I9 $\mathrm{p}$. Ioo de protéines et 0,4 p. Ioo de BHT, présentent une hypertrophie hépatique de $+\mathrm{I}_{5} \mathrm{p}$. Ioo; cette hypertrophie atteint $+30 \mathrm{p}$. Ioo lorsque la concentration de l'additif s'élève à $0,8 \mathrm{p}$. Ioo et nos résultats montrent qu'elle atteint $+24 \mathrm{p}$. Ioo et $+50 \mathrm{p}$. Ioo lorsque la concentration de l'additif s'élève à $0,6 \mathrm{p}$. Ioo et $\mathrm{I}, 2 \mathrm{p}$. Ioo respectivement. Chez le mâle castré, l'hypertrophie est donc proportionnelle à la concentration du BHT dans le régime.

Il n'en est pas de même pour la femelle, chez qui l'hypertrophie hépatique atteint + 4I p. Ioo lorsque le taux de BH'T est de 0,6 p. I00, mais tend ensuite à plafonner, puisqu'elle ne dépasse pas $+4^{8} \mathrm{p}$. Ioo lorsque le taux de l'additif s'élève à I, $2 \mathrm{p}$. Ioo.

Il semble que chez le Porc mâle entier, l'effet de l'antioxygène soit moins marqué, puisque l'hypertrophie hépathique ne dépasse pas $+9 \mathrm{p}$. Ioo et $+\mathrm{I} 4 \mathrm{p}$. Ioo chez des animaux abattus à $\mathrm{I} 20 \mathrm{~kg}$ - $\mathrm{I} 40 \mathrm{~kg}$ après avoir reçu depuis le sevrage des régimes contenant 0,4 p. Ioo et $0,8 \mathrm{p}$. Ioo de $\mathrm{BH}^{\prime} \mathrm{T}$ respectivement (DesMoul. IN et coll., I973).

Pour la concentration de 0,4 p. Ioo de BHT, l'hypertrophie hépatique, chez les castrats et surtout chez les mâles entiers, est à la limite de la signification statistique. On peut raisonnablement penser qu'elle apparaît chez le Porc à partir d'une concentration de $0,2 \mathrm{p}$. Ioo de $\mathrm{BH} T$; cette proportion de l'antioxygène dans la nourriture est à rapprocher de celle de $0,05 \mathrm{p}$. Ioo, à partir de laquelle apparaît l'hypertrophie hépatique chez le Rat : il est à noter que la consommation alimentaire rapportée à l'unité de poids vif est de deux à trois fois moins importante chez le Porc que chez le Rat, à stade de développement équivalent : ceci peut expliquer en partie que les effets du BHT se font sentir chez le Porc pour des concentrations plus élevées.

Les résultats du présent travail montrent que l'hypertrophie hépatique induite par le BHT s'accompagne d'un accroissement du capital protéique de l'organe proportionnel à l'hypertrophie. 
La quantité d'ARN du foie est également fortement augmentée, mais toutefois relativement moins que la quantité de protéines, ce qui différencie quelque peu le Porc du Rat. La quantité d'ARN hépatique n'est pas significativement différente chez les témoins mâles castrés et femelles de Ioo $\mathrm{kg}$; toutefois, cette quantité semble inférieure à celle que contient le foie du mâle entier de même poids (DURAND et coll., I967). De plus, sous l'effet du BH'T, l'augmentation relative du capital ribonucléique est sensiblement plus élevée chez les castrats que chez les femelles.

A poids égal d'animal, la quantité d'ADN hépatique est équivalente chez le mâle castré et chez la femelle, mais elle semble être légèrement supérieure chez le mâle entier (DuRAND et coll., I967). Chez le castrat et la femelle, l'hypertrophie hépatique consécutive à l'ingestion de BH'T est accompagnée d'une stimulation de la synthèse d'ADN. Dans nos conditions expérimentales, cette stimulation est très importante chez le castrat $(+39 \mathrm{p}$. IOO), plus modérée, mais pourtant très nette chez la femelle ( +20 p. IOo).

Si l'on estime que la quantité d'ADN est approximativement de $5000 \mu \mathrm{M}$-bases dans le foie du Porc de $20 \mathrm{~kg}$ (DURAND et coll., I967), cette quantité est multipliée par 2,I chez les castrats et femelles témoins, et par 3 et 2,5 chez les castrats et femelles expérimentaux respectivement, au cours de la période qui conduit les animaux de $20 \mathrm{~kg}$ à Ioo $\mathrm{kg}$. Cependant, on ne sait pas si cette accumulation accrue d'ADN correspond à un nombre plus grand de cellules, à une variation du taux d'une éventuelle polyploïdie, ou à la somme des deux phénomènes. En effet, alors que la polyploïdie a été étudiée chez le Rat par de nombreux auteurs, chez 1'Homme (SwARTZ, I956), chez la Souris, le Bouf, la Brebis, l'Ane, le Chat (CAval,I et coll., I964), rien, à notre connaissance, n'a été publié concernant l'évolution du contenu en ADN des noyaux des hépatocytes porcins.

Finalement, diverses indications suggèrent que le retentissement de l'ingestion de BH'T diffère suivant le sexe de l'animal, en particulier l'ampleur de l'hypertrophie hépatique et l'action stimulante sur la synthèse d'ADN. Ceci est à rapprocher des travaux passés en revue par CoNNEy ( I967) qui laissent à penser que le BHT, en stimulant l'activité des hydroxylases hépatiques dont les stéroïdes sont des substrats, est susceptible d'intervenir dans le métabolisme des hormones sexuelles. Peut-on, dès lors, émettre l'hypothèse selon laquelle le BH'T n'aurait pas les mêmes effets avant et après la maturité sexuelle?

On peut en effet le supposer, car si le jeune Rat mâle peut ingérer librement des quantités de BHT dépassant $500 \mathrm{mg} / \mathrm{kg} / \mathrm{j}$ (PAScAL et coll., I97o), le Rat mâle adulte ne peut en ingérer plus de $300 \mathrm{mg} / \mathrm{kg} / \mathrm{j}$. (DURAND et PASCAL, I973). Il y a là l'objet d'une nouvelle série d'investigations.

\section{Poulet}

\section{Appétit et vitesse de croissance.}

Il ressort de nos résultats que 1'addition de BHT à un régime renfermant 24 p. Ioo de protéines ne provoque pas de modification sensible de l'appétit du Poulet; même pour une concentration de $x, 6$ p. Ioo de l'antioxygène, la légère diminution constatée n'est pas significative.

Par ailleurs, l'addition de BH'T à la ration reste sans effet sur la vitesse de crois- 
sance jusqu'au taux de 0,8 p. Ioo ; toutefois, pour $1,6 \mathrm{p}$. I00, on relève une chute spectaculaire de la vitesse de croissance, qui ne représente alors pas même la moitié de ce qu'elle est chez les témoins. On peut, dès lors, penser que le seuil de tolérance de l'additif est franchi, seuil qui se situerait, dans les conditions expérimentales utilisées, entre 500 et $900 \mathrm{mg} / \mathrm{kg}$ poids vif $/$ jour.

De plus, lorsque ce seuil de tolérance est dépassé, on assiste à une augmentation de 1'indice de consommation, évidemment accompagné d'un gaspillage de protéines alimentaires. On retrouve le phénomène observé chez des Rats recevant un régime contenant $0,2 \mathrm{p}$. Ioo de $\mathrm{BHT}$ et seulement $8 \mathrm{p}$. Ioo de protéines; ainsi, chez le Poulet comme chez le Rat, le régime alimentaire doit comporter des proportions relatives convenables de $\mathrm{BH} T$ et de protéines.

Par ailleurs, il semble que le Poulet, contrairement au Rat et peut-être comme le Porc, ne possède pas de mécanisme de régulation de l'appétit qui lui permette une autolimitation de l'ingestion de l'additif.

\section{BHT et hypertrophie hépatique.}

Chez le Poulet mâle, comme chez les mammifères, l'ingestion de BH'T à forte dose provoque une certaine hypertrophie du foie. Cependant, celle-ci n'excède pas + I3 p. roo lorsque le régime renferme $0,8 \mathrm{p}$. Ioo de 1'additif, et se situe alors à la limite de la signification statistique. On peut penser qu'elle ne devient décelable que lorsque le régime contient au moins $0,4 \mathrm{p}$. Ioo de l'antioxygène, ce qui correspond environ à une ingestion de $250 \mathrm{mg} / \mathrm{kg}$ de poids vif $/$ jour, c'est-à-dire à une dose 5 fois plus forte que celle qui peut provoquer un début d'hypertrophie hépatique chez le Rat.

Chez le Poulet, comme chez les autres espèces étudiées, l'hypertrophie du foie s'accompagne d'une augmentation pratiquement proportionnelle des contenus protéique et ribonucléique de l'organe. En revanche, l'accumulation de DNA n'est pas modifiée : cette différence tranchée entre l'oiseau et les deux mammifères, qui présentent d'ailleurs sur ce point des différences entre eux, reste inexpliquée.

A notre connaissance, le taux de polyploïdie des hépatocytes de Poulet n'a pas été étudié, non plus que celui des hépatocytes de Porc; toutefois, dans le cas du Poulet, la quantité d'ADN n'étant pas modifiée, il y a tout lieu de penser que l'hypertrophie hépatique est due exclusivement à l'hypertrophie des hépatocytes.

Reçu pour publication en janvier 1974.

\section{SUMMARY}

PROTEIN AND NUCLEIC ACID CONTENT OF THE HYPERTROPHIED

LIVER AFTER FREE INTAKE OF DI-TERTIO-BUTYI,-HYDROXY-TOLUENE (BHT)

IN THE GROWING RAT, PIG AND CHICKEN.

EFFECT OF PROTEIN CONTENT OF THE RATION

The effects of BHT intake on appetite, growth rate and hepatic hypertrophy are studied in the growing rat, pig and chicken. Hepatic hypertrophy is studied as related to the accumulation of protein $(\mathrm{N} \times 6.25)$ and nucleic acids, DNA in particular. In the rat, effects of the antioxygen on these same factors are examined in terms of the protein content of the diet. 
Lots of male rats are fed diets containing $0.2 \mathrm{p}$. 100 of BHT and 8 p. I00, I 3 p. I00 or I 8 p. 100 of protein. Lots of castrated male or female pigs are given diets containing $0.6 \mathrm{p}$. Ioo or $\mathrm{x} .2 \mathrm{p}$. Ioo of BHT and I9 p. Ioo of protein. Lots of male chickens are fed diets having 0.2 p. I 00 to I.6 p. Ioo of BHT and $24 \mathrm{p}$. 100 of protein. These lots are compared to ad libitum fed control goups, and eventually to restricted control group.

The results show the following facts :

- addition of BHT of the diet at a concentration of $0.2 \mathrm{p}$. Ioo slightly reduces the appetite of rats (from - 3 p. 100 to $-8.5 \mathrm{p}, 100$ ) ; however, addition of the antioxygen has no effect on the appetite of pigs, even at a concentration of I.2 p. Ioo, nor on the appetite of chickens even at a concentration of 1.6 p. Ioo;

- growth rate of rats fed a diet containing 0.2 p. roo of BHT is equal to that of the corresponding restricted controls when the protein content of the diet is sufficient ( 3 p. Ioo and I 8 p. Ioo, but it is lower when protein concentration is insufficient $(8 \mathrm{p}$. IOo). Growth rate in pigs is unchanged, even when antioxygen content in the diet reaches I.2 p. 10o. Chicken growth rate is unchanged with a concentration of 0.8 p. Ioo, but decreases by 55 p. Ioo with a concentration of I.6 p. Ioo.

- the addition of BHT in the diet causes hepatic hypertrophy in the three species but at different concentrations, the rat being the most sensitive followed by the pig and the chicken. Hepatic hypertrophy is usually accompanied by proportional increases of protein content and liver RNA. On the contrary, the effect of BHT on hepatic accumulation of DNA varies according to species. It has no effect in the chicken and a stimulating effect in the pig and the rat. However, the stimulating effect in the rat is counterbalanced by autorestrictive feeding.

\section{RÉFÉRENCES BIBLIOGRAPHIQUES}

Brown W. D., Johnson A. R., O'Halloran, 1959. The effect of the level of dietary fat on the toxicity of phenolic antioxidants. Aust. J. exp. Biol., 37, 533-548.

Cavalli G., Bortolami R., Orlandi F., Scardovi I., I964. Della relazione tra contenuto in acido desossiribonucleico (ADN) e volume nucleare degli epatociti mononucleati in varie specie di mammiferi. Bioch. Biol. Speriment., 3, 304-342.

Conney A. H., 1967. Pharmacological implications of microsomal enzyme induction. Pharmacol. Rev. 19, 317-366.

Deichman W. B., Clemmer J. J., Rakoczy R., Bianchine J., i955. Toxicity of ditertiarbutylmethylphenol. Arch. Ind. Health, 11, 93-Ior.

Desmoulin B., Pascal G., Durand G, i972. Addition d'un antioxygène (BHT) dans l'alimentation du Porc mâle castré : constitution des graisses résidus tissulaires. 18th European Meeting of meat Research Workers, Guelph (Canada), 286-292.

Desmoulin B., Dumont B. L., Pascal G., I973. Qualité des carcasses et des viandes de Porcs mâles entiers de $120 \mathrm{~kg}$ et $140 \mathrm{~kg}$. Addition de BHT aux régimes Mais Soja ou Orge Soja. J. Rech. Porc. en France, Paris, $20 \mathrm{I}-209$.

Durand G., Fauconneau G., Penot E., I967. Croissance des tissus du Rat et réduction de l'apport énergétique de la ration; influence sur la teneur en acides nucléiques. Ann. Biol. anim. Bioch. Biophys., 7, I 45 -I 55 .

Durand G., Fauconneau G., Penot E., I967. jivolution des teneurs en acides nucléiques et en protéines du foie du Porc au cours de la croissance post-natale. Bull. Soc. Chim. Biol., 49, 36r-370.

Durand G., Fauconneau G., Penot F., ig69. Répartition des cellules entre les tissus du Rat adulte, préalablement soumis à une sous nutrition énergétique temporaire à deux stades de la croissance. Ann. Biol. anim. Bioch. Biophys., 9, 55-73.

Duránd G., Penot E., 197o. Effets du maintien à poids constant pendant de longues durées chez le Rat sevré. Reprise de la croissance. Ann. Biol. anim. Bioch. Biophys., 10, 385-399.

Durand G.,I972. Quelques données sur la longévité du Rat et de la Souris soumis : a) à des régimes alimentaires additionnés d'agents antioxygènes; $b$ ) à des restrictions alimentaires. Expérimentation animale, 5, $291-307$.

Durand G., Pascal G., I973. Effets du di-tertio-butyl-hydroxy-toluène (BHT) ajouté en concentration croissante dans la ration, sur l'appétit et le poids vif du Rat mâle adulte. Influence du taux protéique. Ann. Nutr. Alim., 27, I I-24.

Durand G., 1973. Effets comparés de restrictions protéiques et de restrictions énergétiques sur les contenus en protéines et en acides nucléiques des tissus du Rat en croissance. Ann. Biol. anim. Bioch. Biophys., (sous presse).

Frawley J. P., KoHN F. E., KAY J. H., CALANdra J. C., I965. Progress report on multigeneration reproduction studies in Rat fed butylated hydroxytoluene (BHT). Food Cosmet. Toxicol., 3, 377-386. 
Garner R. C., McLean A. E., 1969. Increased susceptibility to carbon tetrachloride poisoning in the Rat after pretreatment with oral phenobarbitone. Biochim. Pharmacol, 18, 645-650.

Gaunt I. F., Feuer G., Fairweather F. A., Gilbert D., I965 a. Liver response tests. IV. Application to short term feeding studies with butylated hydroxytoluene (BHT) and butylated hydroxyanisole (BHA). Food Cosmet. Toxicol., 3, 433-443.

Gaunt I. F., Gilbert D., Martin I., rg65 b. Liver response tests. V. Effect of dietary restriction. on a short term feeding study with butylated hydroxytoluène (BHT). Food Cosmet. Toxicol., 3, 445-456.

Gilbert D., Golberg L., tg65. Liver response tests. III. Liver enlargement and stimulation of microsomal processing enzyme activity. Food Cosmet. Toxicol., 3, 4I7-432.

Gilbert D., Goldberg L., 1967. BHT-uxydase. A liver microsomal enzyme induced by the treatment of Rats with butylated hydroxytoluène. Food Cosmet. Toxicol., 5, 481-49o.

Gontzea I., Sutzesco P., Cocora D., Lungu D., I964. Importance de l'apport de protéines sur la résistance de l'organisme à l'intoxication par le plomb. Arch. Sci. Physiol., 18, 2I I-224.

Gontzea I., Bistriceanu E., Draghicesco M., Manea M., 1968. Le rôle des protéines dans l'intoxication chronique au toluène. Arch. Sci. Physiol., 22, 394-409.

Johnson A. R., Holdsworth E. S., 1968. The effect of the antioxydant butylated-hydroxy-toluene on the lipid metabolism of the Rat. $J$. Nutr. Dietet., 5, I47-I53.

Kerr R., Lefevre A., Lane B. P., Lieber C. S., 1966 . Liver growth induced by butylated hydroxytoluène (BHT). Clin. Res., 14, 299.

LANE B. P., LIEBER C. S., I967. Effects of butylated hydroxytoluène on the ultrastructure of Rat hepatocytes. Lab. Invest., 16, 342-348.

March B. E., Biely J., Coates V., ig68. The influence of diet on toxicity of the antioxydant I, 2-dihydro-6-éthoxy-2, 2, 4-triméthylquinoline. Canad. J. Physiol. Pharmacol., 46, I45-I 49.

MILNER S. M., I967. Effects of the food additive butylated hydroxytoluene on monolayer cultures of primate cells. Nature, 216, $557-560$.

Nadal C., Zajdela F., I966. Polyploïdie dans le foie de Rat. II. Le rôle de l'hypophyse et de la carence protéique. Exptl. Cell Res., 42, I I7-I29.

Pascal G., Terroine T., I969a. Effets biochimiques et physiologiques d'un additif alimentaire : le di-tertio-butyl-hydroxy-toluène (BHT). Ann. Nutr. Alim., 23, I5-62.

Pascal G., Terroine T., I969 b. Influence du butyl-hydroxy-toluène (BHT) sur l'activité de la cyto. chrome oxydase du foie de Rat. C. R. Acad. Sci. Paris, 268, I529-I53I

Pascal G., 1969. Influence de l'ingestion de butyl-hydroxy-toluène (BHT) sur l'activité de la phosphatase acide du foie de Rat. Ann. Nutr. Alim., 23, 73-Ior.

Pascal G., Durand G., Penot E., I97o. Influence de l'ingestion de di-tertiobutyl-hydroxy-toluene (BHT) sur la croissance corporelle et la composition du tissu hépatique du Rat blanc. Arch. Sci. Physiol., 24, 37-54.

Pascal G., Durand G., ig7o. Influence du Butyl-hydroxy-toluène (BHT) sur 1'accumulation des lipides dans l'organisme du Rat. J. Physiol, Paris, 62, supplément I, 201-202.

PASCAL G., 197r. Effets métaboliques d'un additif alimentaire à propriété anti-oxygène : le BHT. $J$. Physiol., Paris, 63, 260-26I A.

Pascal G., Terroine T., I972. Effets de l'ingestion d'un additif alimentaire, le di-tertio-butylhydroxy-toluène (BHT) sur les échanges respiratoires du Rat mâle. Ann. Nutr. Alim., 26, 33-52.

Pascal G., 1974. Physiological and metabolic effects of antioxydant food additives. World Rev. Nutr. Diet., 19, 237-299

Sporn A., Schobesch O., I96r. Research on the toxicity of butylated hydroxytoluene. Ig. Microbiol. Epidem. Buc., 9, I I3, d'après Gaun et coll. Food Cosmet. Toxicol., 1965, 5, 433-443.

Sugahara M., Baker D. M., Harmon B. G., Jensen A. H., I969. Effect of excess level of dietary crude protein on carcass development in Swine. J. anim. Sci., 29, 598-60r.

Swartz F. J., I956. The development in the human liver of multiple DNA classes and their relationship to the age of the individual. Chromosoma, 8, 53-6I. 